\title{
URBANIZAÇÃO EXTENSIVA E RECONFIGURAÇÃO RURAL NA AMAZÔNIA: UMA PROPOSTA TEÓRICO- METODOLÓGICA BASEADA EM INDICADORES DEMOGRÁFICOS E ESPACIAIS
}

\author{
Julia Corrêa Côrtes* \\ Álvaro de Oliveira D'Antona ** \\ Ricardo Ojima*** \\ * Universidade Estadual de Campinas, Núcleo de Estudos e Pesquisas Ambientais, Campinas, SP, Brasil. \\ ** Universidade Estadual de Campinas, Faculdade de Ciências Aplicadas, Campinas, SP, Brasil. \\ *** Universidade Federal do Rio Grande do Norte, Departamento de Demografia e Ciências Atuariais, Natal, \\ RN, Brasil.
}

\begin{abstract}
Resumo
Este trabalho resulta da reconstrução teórico-conceitual realizada para verificar empiricamente a existência de urbanização extensiva na Amazônia com base na incorporação de noções demográficas ao referencial em questão. Observouse como o tecido urbano contribui para a reconfiguração rural, evidenciando as múltiplas dimensões que perpassam o fenômeno urbano. Com indicadores demográficos sensíveis aos processos socioespaciais urbano-rurais, foram analisados territórios rurais de dois recortes regionais no oeste do estado do Pará. Os resultados confirmam que a propagação dos vetores urbanos tende a intensificar a aglomeração populacional (coeficiente de Gini) e a predominância espacial de mulheres (razão de sexo) por mecanismos de diferenciações espaciais. A existência de um eixo de mobilidade populacional, o regime de ocupação e a distância do centro urbano são os elementos estruturantes da emergência de um mosaico de ruralidades imersas em contextos urbanos. Com os resultados, concebeu-se um modelo teórico-metodológico com uma abordagem analítica inédita na literatura sobre urbanização.

Palavras-chave

Transição urbana; Ruralidades; Distribuição populacional; Amazônia brasileira.
\end{abstract}




\title{
EXTENDED URBANIZATION AND RURAL RECONFIGURATION IN THE AMAZON: A \\ THEORETICAL-METHODOLOGICAL PROPOSAL BASED ON DEMOGRAPHIC AND SPATIAL INDICATORS
}

\author{
Julia Corrêa Côrtes* \\ Álvaro de Oliveira D'Antona ** \\ Ricardo Ojima** \\ * Universidade Estadual de Campinas, Núcleo de Estudos e Pesquisas Ambientais, Campinas, SP, Brazil. \\ ** Universidade Estadual de Campinas, Faculdade de Ciências Aplicadas, Campinas, SP, Brazil. \\ *** Universidade Federal do Rio Grande do Norte, Departamento de Demografia e Ciências Atuariais, Natal, \\ RN, Brazil.
}

\begin{abstract}
This paper unfolds to develop a new theoretical-conceptual reference about urbanization, working with demographic parameters into the extended urbanization theory. We intend to explore how the urban tissue contributes to the rural reconfiguration in the Brazilian Amazon fostering the multiples dimensions of urban phenomenon. Based on demographic indicators that are sensitive to socio-spatial processes, we build a methodological framework to analyze rural landscapes of two areas in the west side of Pará state, in Brazil. The results confirm that propagation of urban vectors tends to intensify the population agglomeration (Gini Index) and the women predominance (Sex Ratio) by mechanisms of spatial differentiation. The existence of a mobility axis, the population settlement regime and the distance from the urban center are the structural elements for creating a mosaic of ruralities immersed in urban contexts. With our findings, we conceived a theoretical-methodological model with an analytical approach unprecedented in the literature on urbanization.
\end{abstract}

Keywords

Urban transition; Ruralities; Population distribution; Brazilian Amazon. 


\title{
URBANIZAÇÃO EXTENSIVA E RECONFIGURAÇÃO RURAL NA AMAZÔNIA: UMA PROPOSTA TEÓRICO-METODOLÓGICA BASEADA EM INDICADORES DEMOGRÁFICOS E ESPACIAIS
}

\author{
Julia Corrêa Côrtes \\ Álvaro de Oliveira D’Antona \\ Ricardo Ojima
}

Introdução

A transição urbana já pode ser considerada um processo global inexorável e que ocorreu mais intensamente nos últimos anos (UN, 2014; COHEN, 2004). No panorama latino-americano, o Brasil destaca-se pela precocidade e pela velocidade com que esse processo se efetivou, o que reverberou na concentração de mais de $80 \%$ da população vivendo em áreas classificadas como urbanas, segundo dados do Censo Demográfico de 2010. A despeito do estágio avançado da transição urbana no país, há nessas trajetórias particularidades regionais e desigualdades. Especificamente no tocante à região Norte do Brasil, o início tardio do processo de transição explica os níveis de urbanização situados abaixo do das demais regiões, ficando atrás apenas da região Nordeste, apesar de a taxa de crescimento da população urbana na região Norte estar acima de média nacional (MARTINE; MCGRANAHAN, 2010).

Na porção norte do país, a região em que se insere o bioma amazônico é compreendida como uma floresta em franco processo de urbanização, com vasta e detalhada literatura dedicada a compreender suas especificidades e sua diversidade, assim como suas conexões regionais e globais, as relações econômicas e sociais, o papel das cidades nas conexões rural-urbana, entre outros temas (DA COSTA; ROSA, 2017; BROWDER; GODFREY, 1997; BECKER, 1995; 2005; 2013; CASTRO, 2006; 2009; GUEDES; COSTA; BRONDÍZIO, 2009; PADOCH et al., 2008; PEREIRA, 2006; SCHMINK; WOOD, 1992; SCHOR et al., 2014; TRINDADE JÚNIOR, 2011). O reconhecimento 
da região como uma floresta urbanizada tem como aporte demográfico indicadores fundados no referencial da transição urbana (SKELDON, 1990), apurada com base no volume populacional e na proporção de habitantes urbanos. Caracteriza-se, portanto, por análises que consideram o número e o tamanho das cidades, a taxa de crescimento populacional e a distribuição da população rural-urbana.

Entretanto, reconhecemos que, para abarcar a complexidade urbana da região da Amazônia brasileira, como tem sido descrita, seria necessário repensar o desenho metodológico. A abordagem tradicional reproduz componentes macroestruturais com pouca, ou nenhuma, aderência aos processos sociais que caracterizam o modo de vida urbano. Embora a dimensão social da urbanização na Amazônia seja objeto de discussão e estudos, são poucos os trabalhos que desenvolvem instrumentos analíticos sensíveis a fatores não apenas volumétricos ou de distribuição quando se trata da população. Neste sentido, para contemplar a multidimensionalidade do fenômeno urbano e as dinâmicas híbridas das territorialidades amazônicas, adotamos a referência de urbanização extensiva (MONTE-MÓR, 1994), que amplia a ideia de urbanização para além dos núcleos consolidados na conformação de um tecido urbano, sem se restringir às feições usualmente tipificadas de forma dicotômica em "urbano" ou "rural".

Os dados e análises foram sistematizados considerando o processo histórico das trajetórias urbanas em duas sub-regiões no oeste do Pará, entre os municípios de Santarém e Altamira (Figura 1). Ainda que não se possa tomar a parte (o estudo de caso) pelo todo (a região Amazônica), a área de estudo é pertinente para a investigação sobre urbanização na Amazônia, pois apresenta: a) coexistência de áreas de ocupação antiga (consolidadas) e recentes; b) diversidade de formas de ocupação populacional, incluindo assentamentos agrícolas, Unidades de Conservação, Terras Indígenas e centros urbanos de portes variados; c) posição geográfica, com a incorporação de elementos estruturantes da urbanização, como as rodovias federais e os rios de grande porte; d) e destaque no cenário amazônico, dada a relevância econômica e demográfica. Por tais motivos, o estudo da sub-região da Amazônia Ocidental aqui considerada pode lançar luzes sobre o contexto regional, apesar da diversidade de configurações intrarregionais, ensejando outros estudos de caso e a inclusão de outros processos. 


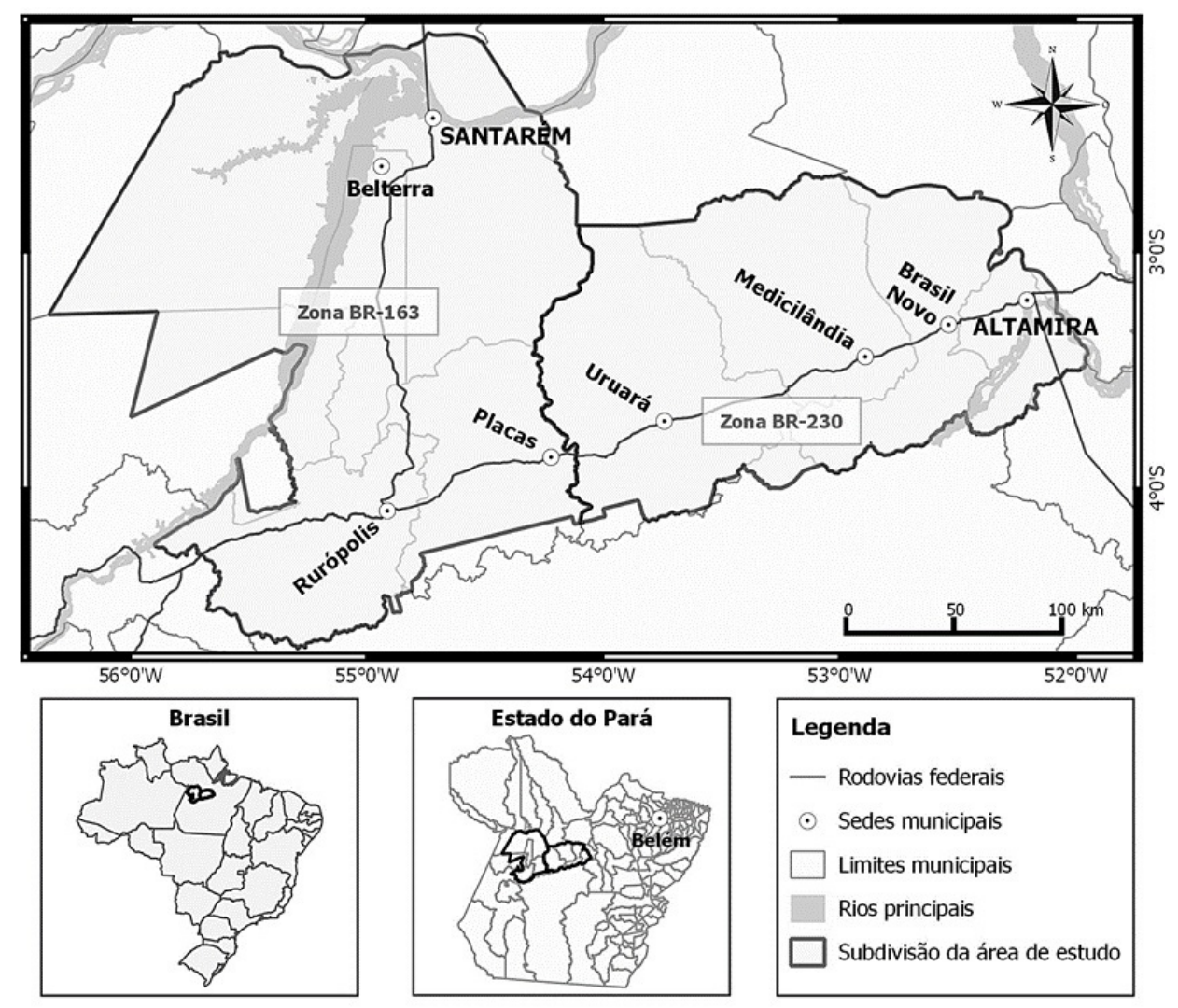

Figura 1. Área de estudo e as duas sub-regiões de análise localizadas no estado do Pará, Brasil. *A área de estudo contempla parcial ou integralmente os territórios de oito municípios, conforme demarcação referente ao ano de 2010.

Fonte: Elaboração dos autores.

Com base nesse quadro, definimos dois questionamentos norteadores do trabalho. O primeiro consiste em compreender como o tecido urbano se desenvolve no espaço rural em face de sua heterogeneidade - um mosaico de ruralidades. $\mathrm{O}$ segundo, espera-se que reflita o modo como diferentes contextos urbanos interferem na força dos vetores de expansão e consolidação do tecido urbano. As duas abordagens investigativas se fundem para amparar o objetivo geral do trabalho, qual seja: verificar empiricamente a urbanização extensiva e seus mecanismos de reconfiguração rural da Amazônia brasileira, valendo-nos do caso estudado, a fim de subsidiar a formulação de um modelo teórico-metodológico sob uma perspectiva de mensuração urbana que não se resuma a volumes populacionais e sua distribuição espacial.

Para a análise, incorporamos sistematicamente noções demográficas aos conceitos e processos presentes no referencial de urbanização extensiva (MONTE-MÓR, 1994). Reforçamos a urbanização como um fenômeno demográfico espacial 
(PEBLEY, 1998) - uma expressão da concentração de pessoas, bens e capitais - e definimos a urbanização como um produto de racionalidades e usos da terra, portanto, uma combinação das morfologias material e social do fenômeno urbano. Os resultados confirmam diferentes intensidades de reconfiguração das funcionalidades e significâncias dos espaços rurais na conformação de um tecido urbano amplo, dinâmico e heterogêneo. Contribuímos, com isso, para a concepção de uma visão mais plural do fenômeno urbano e para novos aportes analíticos de mensuração e avaliação.

\section{Fundamentos teóricos sobre a urbanização}

A narrativa tradicional sobre urbanização sugere uma trajetória marcada pela transformação econômica da sociedade agrícola para a industrial (MARTINE; MCGRANAHAN, 2010). A teoria da Transição Urbana, originalmente postulada por Skeldon (1990), estrutura-se nas descrições da transição demográfica e da dinâmica migratória para descrever a urbanização como uma tendência de concentração da população em ocupações urbanas de alta densidade - com maior oportunidade de educação e trabalho em virtude das atividades econômicas industriais e da concentração de serviços (MONTGOMERY et al., 2003). As abordagens dessa construção teórica são amparadas pelo levantamento do número absoluto de população urbana e de seu crescimento, pela mudança no quadro do tamanho dos municípios e, igualmente, pelo aumento na proporção da população urbana.

Acreditamos que essa perspectiva teórico-empírica fomenta uma percepção antagônica de rural versus urbano, reiterando a defasada dicotomia entre rural-campo e urbano-cidade. Enquanto o embasamento teórico se funde em elementos macroestruturais, a definição desses espaços se constitui em instrumentos fiscais que se orientam por questões político-administrativos - reduzindo urbano e rural ao papel de adjetivos territoriais (ENDLICH, 2006). As críticas a esse modelo dicotômico são vastas e de diferentes frentes disciplinares, com o pleno consenso científico de sua limitação na representação da complexidade dos espaços e dos desafios em analisá-los (CAIADO; SANTOS, 2003; CASTRO, 2006; CHAMPION; HUGO, 2003; SILVA, 2001; WANDERLEY, 2000).

A urbanização propicia a emergência de uma zona de transição entre o urbano e o rural onde ocorrem transformações de seus aspectos físicos e sociais, dissolvendo a nitidez de seus limites (SPOSITO, 2006). O rural e o urbano tendem a se inter-relacionar em um processo de convergência de estilos de vida, que marca uma passagem gradual, contínua, sem ruptura (CHAMPION; HUGO, 2003; WANDERLEY, 2000). Essa ideia se expressa também no conceito de continuum urbano-rural, em que o polo urbano assume o papel de dissipador de valores e prá- 
ticas, ao integrar e conectar os extremos por meio de uma escala de intensidades, e não de contrastes (MARQUES, 2002; WANDERLEY, 2000). A aplicação do conceito continuum urbano-rural é variada e também passível de crítica, na medida em que conserva a dualidade de polos e expressa um mecanismo de transição que leva à completa urbanização com eliminação do espaço rural (WANDERLEY, 2000).

Essa perspectiva expõe a multiplicidade de configurações rurais, superando o paradigma rural-agrícola. Ao propor um renascimento do rural, Kayser (1990) enfatiza que sua representação emana do modo de vida e da identidade ("lugar onde se vive") e de sua inserção nas esferas mais amplas da sociedade ("lugar onde se vê e vive o mundo") - trata-se, portanto, de um modo particular utilizar o espaço e a vida social. As novas relações socioespaciais e o exercício da pluriatividade mostram a face maleável do rural, que se recria apoiado em vínculos culturais e referências identitárias. A urbanização, de um fenômeno de homogeneização espacial e social, transforma-se em um processo que desencadeia a emergência de novas ruralidades imersas em contextos urbanos (MARQUES, 2002; WANDERLEY, 2000).

A distinção entre esses espaços não é eliminada, mas suas funções e conteúdos deixam de ser contraditórios e se tornam constituintes de um tecido urbano (LEFEBVRE, 1999). Henry Lefebvre prevê a urbanização completa da sociedade por meio da dialética da implosão-explosão das cidades, em uma tendência de aglomeração e intensificação da densidade no polo urbano e em sua expansão horizontal. O espaço rural estaria, então, cada vez mais entrelaçado pelo tecido urbano na conformação de uma sociedade urbana, representado por meio da produção do espaço na sua morfologia material - transformações físicas ligadas à concepção da cidade, como infraestrutura e edificações - e social - transformações no modo de vida ligadas à concepção do urbano, como valores e cotidiano (ENDLICH, 2006; MARQUES, 2002; MONTE-MÓR, 2006).

A urbanização extensiva, conceito apresentado por Monte-Mór (1994), permite compreender a urbanização como uma transformação da sociedade e seus valores, resultante, também, da emergência de novas ruralidades - ou urbanidades. Nesse referencial, cada ruralidade se conecta ao centro urbano por meio de suporte às atividades socioeconômicas, identificadas, portanto, como paisagens operacionais da urbanização. Dessa forma, a urbanização se estende para além das cidades e se propaga em redes que penetram virtualmente os espaços, constituindo o tecido urbano (BRENNER; SCHMID, 2015; MONTE-MÓR, 1994).

Essa construção teórica destaca-se por incorporar a questão sociológica inerente à urbanização - minimizada, senão ausente, nas abordagens investigativas pautadas na transição urbana. Entendemos que trabalhar as múltiplas dimensões 
que perpassam o fenômeno urbano é uma estratégia favorável para enfrentar a complexidade dos processos contemporâneos. O desafio que enfrentamos foi o de transcorrer do plano teórico para o analítico minimizando simplificações nos procedimentos metodológicos. Assumimos que o ponto de conexão entre as morfologias material e social da urbanização decorre de processos socioespaciais, o que nos possibilitou pensar em uma demografia espacial para complementar o referencial de urbanização extensiva e verificar como o tecido urbano contribui para a reconfiguração rural na Amazônia.

\section{Metodologia da pesquisa}

Caracterização das sub-regiões na área de estudo

A decisão de desenvolver uma análise comparativa das duas sub-regiões (Figura 1) justifica-se pela necessidade de discutir a força de propagação dos vetores morfológicos urbanos em contextos de maior ou menor intensidade urbana. Além disso, ampara nossa crítica sobre o uso generalizado do indicador de proporção de pessoas vivendo em áreas classificadas como urbanas, uma vez que as duas sub-regiões apresentam o mesmo grau de urbanização, mas com expressividade urbana distinta, decorrente de suas trajetórias históricas de constituição.

A definição e a demarcação desse zoneamento seguiram três condições. A primeira delas consistiu em incorporar um componente fluvial nas duas sub-regiões, com o propósito de ampliar a percepção temporal dos contextos urbanos trabalhados, tendo em vista a importância dos rios. A segunda, em respeitar os eixos rodoviários principais, pois estes ajudam a orientar os fluxos de capitais e pessoas, ao estruturar a lógica dos territórios municipais e da circulação interna. Com relação à terceira, tratou-se de acatar o processo de emancipação dos municípios valendo-nos de seus contornos originais, em que se valoriza a perspectiva histórica da urbanização regional. Essa abordagem também permite a manutenção da correspondência espacial ao longo dos censos demográficos, fundamental para análises longitudinais.

À primeira sub-região de análise, denominada Zona-BR163, pertencem os municípios de Santarém, Belterra, Rurópolis e Placas'. Caracteriza-se por sua longa história de ocupação, conectada especialmente à trajetória de Santarém, referência urbana na Amazônia já em 1828, período da exploração da borracha. Na posição estratégica entre os rios Amazonas e Tapajós, e equidistante das capitais Belém e Manaus, o município de Santarém é importante ponto de transição no fluxo de pessoas e mercadorias. A abertura da fronteira agrícola em 1970 e a construção

1. E, mais recentemente, o município de Mojuí dos Campos, desmembrado de Santarém em 2013. 
da Rodovia BR-163 impulsionaram sua urbanização e concentraram a maioria da população no urbano já em 1980. Ao longo da década seguinte, Placas e Belterra emanciparam-se de Santarém.

Pertencem à segunda sub-região de análise, denominada Zona-BR230, Altamira, Brasil Novo, Medicilândia e Uruará. Com uma dinâmica mais recente, a região se constituiu a partir de Altamira, município que se estabeleceu na margem do Rio Xingu formalmente em 1911, mas que se destacou depois da implantação dos planos da fronteira agrícola em 1970, quando foi nomeado o marco zero da Transamazônica (BR-230). Desse momento em diante, observam-se as principais transformações na região, incluindo os desmatamentos com característica "espinha de peixe”, decorrentes das ocupações espontâneas ou conduzidas pelo Estado nas faixas adjacentes à rodovia (BECKER, 2001). Dos povoados e agrovilas em expansão constituíram-se os municípios ao longo da BR-230, emancipados durante a década de 1980 e 1990. A partir de 2000 ocorreram novas e intensas transformações com a aprovação da licença da Hidrelétrica de Belo Monte, fato que desencadeou um novo dinamismo na região (FEARNSIDE, 2015).

\section{Método de definição das paisagens urbanas}

Para avaliar a urbanização extensiva (Monte-Mór, 1994), definida pela emergência de novas ruralidades que se entrelaçam ao núcleo urbano na conformação de um tecido virtual, foram definidas como unidade analítica as paisagens urbanas, em referência às paisagens operacionais, como apresentam Brenner e Schmid (2015). Considerando os desafios de teorizar e mapear novas formações urbanas, neste trabalho adotou-se o critério de exposição e absorção dos vetores da morfologia social e material da urbanização. As paisagens urbanas, que representam as diferentes ruralidades no espectro do tecido urbano, foram determinadas pela proximidade com o núcleo urbano e com questões normativas dos territórios, de forma a incorporar os diferenciais que condicionam direta e indiretamente a mobilidade das pessoas e os usos da terra.

Como resultado, foram determinadas seis Paisagens Urbanas: Entorno Urbano, Rodovias, Unidade Agrícola, Unidade Ambiental e Outras Urbanidades, além do Núcleo Urbano². Esse mosaico de ocupação foi construído com o aporte de técnicas de geoprocessamento, tendo como fonte o Instituto Brasileiro de Geografia e Estatística (IBGE) e o Instituto Nacional de Colonização e Reforma Agrária (Incra).

2. Apesar de os rios ainda exerceram um papel relevante no sistema de fluxos da Amazônia, por questões técnicas de análise os cursos fluviais não foram incorporados na construção das paisagens, já que praticamente toda sua área de influência (buffer) na área de estudo estaria sobreposta aos eixos de regularização fundiária (Unidades de Conservação, Assentamentos Agrícolas e Terras Indígenas). 
A configuração final das paisagens urbanas determinadas como as unidades analíticas do estudo está representada na Figura 2.

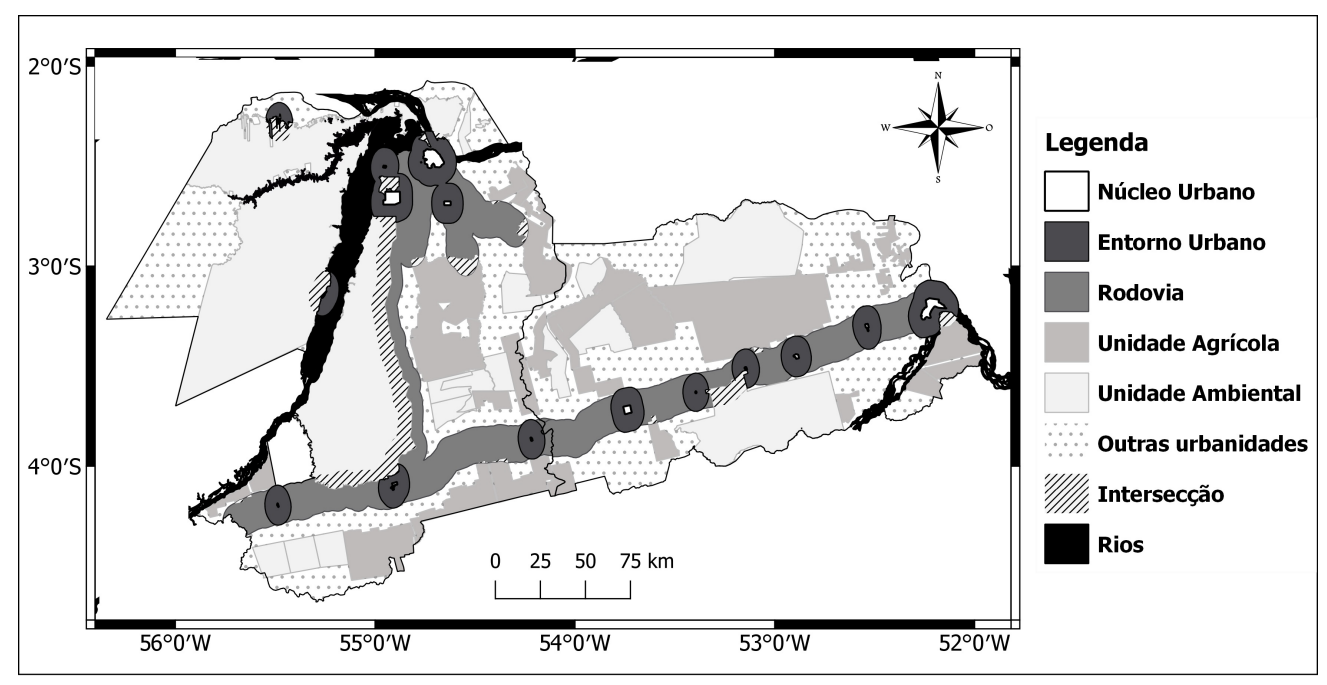

Figura 2. Configuração espacial das paisagens urbanas na área de estudo. Fonte: Elaboração dos autores.

O Núcleo Urbano é a representação da máxima aglomeração e faz referência ao polo urbano no continuum urbano-rural. É definido por determinação administrativa, de acordo com a classificação da situação do setor censitário em 2010 do IBGE (2010). A paisagem Entorno Urbano é construída tendo como ponto de partida uma área de influência (buffer) de 10 quilômetros do Núcleo Urbano. A paisagem Rodovia, por sua vez, considera o entorno de 10 quilômetros em ambas as margens das rodovias federais - Transamazônica (BR230) e Cuiabá-Santarém (BR163) - e nas principais estradas estaduais, descartando o efeito de outras estradas para a obtenção de um mapa temático menos fragmentado. A determinação de 10 quilômetros da área de influência do urbano e das rodovias resultou de um conjunto de testes com vistas a atenuar a perda de dados e a capacidade explicativa dos resultados por sobreposição com outras paisagens adotadas no estudo.

As áreas de regularização fundiária são categorizadas conforme a natureza de suas propostas de criação. A paisagem Agrícola contempla as unidades de estímulo à ocupação e uso da terra - como os projetos de assentamento agrícola. A paisagem Ambiental incorpora unidades de contenção populacional e restrição ao uso da terra - Unidades de Conservação, Terras Indígenas, Projetos de Desenvolvimento Sustentável, Projetos de Assentamento Agroextrativista. E a paisagem Outras Urbanidades representa as áreas não incluídas nas demais categorias. 
O processo de construção dessas camadas gerou as áreas de intersecção. $\mathrm{Na}$ presença do Núcleo Urbano, manteve-se a predominância deste sobre os demais. As outras situações foram descartadas da análise para reduzir a complexidade de elementos investigativos - por exemplo, a sobreposição de entorno da Rodovia com uma Unidade de Conservação. A delimitação final da área de estudo segue a demarcação dessas paisagens urbanas, de tal forma que, em diversos pontos, o limite administrativo do município foi desconsiderado para incorporar integralmente determinada área de ocupação. Em função da vasta extensão do município de Altamira, o recorte espacial priorizou a porção norte, que participa ativamente da dinâmica da BR-23o e da rede hierárquica urbana dos demais municípios.

\section{Construção dos indicadores demográficos}

A definição de variáveis capazes de representar a espacialidade da urbanização como fenômeno demográfico e a expressividade urbana presente nas paisagens urbanas evocam o desafio de encontrar alternativas ao indicador grau de urbanização, ou taxa de urbanização, que consiste no percentual da população total residindo em áreas urbanas (SKELDON, 1990). Usado de forma convencional e monolítica, o grau de urbanização apresenta algumas limitações teórico-operacionais: desconsidera a diversidade de ocupações e territorialidades (percepção simplificada do rural e antagônica ao urbano); não pondera a história dos municípios e seus contextos urbanos (percepção linear do processo de urbanização); não reflete a real apropriação social, espacial e mesmo demográfica do urbano (percepção unidimensional da urbanização); depende de definições legais de limites político-administrativos (percepção cartesiana do espaço) - não são raras as críticas desenvolvidas sobre os critérios oficiais de definição do urbano no Brasil.

Para captar a multidimensionalidade do fenômeno urbano, nós nos propusemos trabalhar com indicadores que fossem mais sensíveis aos processos socioespaciais urbano-rurais. Alternativamente ao grau de urbanização, utilizamos como indicadores o Coeficiente de Gini e a Razão de Sexo. O Coeficiente de Gini pode ser aplicado a qualquer distribuição; nós fizemos uso dessa medida de desigualdade para indicar a tendência de aglomeração ou de dispersão da população no espaço de análise. Expresso em equivalência numérica de porcentagem, varia de o a 1 com o correspondente à completa igualdade. A Razão de $\mathrm{Sexo}^{3}$, uma medida da composição da população que expressa o número de homens a cada cem mulheres, aqui se aplica para indicar o processo de feminização conectado à urbanização e o caráter masculino das áreas rurais (CAMARANO; ABRAMOVAY, 1999; DINIZ, 2002).

3. O valor é o produto da razão entre o número de homens por mulheres multiplicado por 100. 
Para essas análises, usamos os dados do universo do Censo Demográfico 2010 organizados em uma grade regular com células de $1 \mathrm{~km}^{2}$ nas áreas rurais e de $250 \mathrm{~m}^{2}$ nas áreas urbanas, aproximadamente (IBGE, 2016), processados em um Sistema de Informações Geográficas para a extração das informações segundo as divisões das sub-regiões da área de estudo. As células propiciam melhor resolução espacial do dado e são mais adequadas aos recortes intramunicipais e não aderentes a limites político-administrativos (D’ANTONA; BUENO, 2016).

A discussão do trabalho baseia-se nos resultados dos indicadores demográficos para cada paisagem urbana e por sub-região de análise. Inicialmente, analisamos variações da dispersão populacional ao longo do tecido urbano, amparando a discussão nos diferenciais referentes à exposição e à suscetibilidade das paisagens em absorver os vetores morfológicos urbanos. Na sequência, verificamos as diferenças entre as duas sub-regiões da área de estudo para analisar como varia a composição da população conforme as intensidades urbanas. Ao final, convergimos as duas discussões em um modelo teórico sobre os mecanismos da urbanização extensiva na Amazônia.

\section{Resultados e discussão}

O tecido urbano no meio rural: resultados das variações no índice de dispersão populacional

A análise da dispersão populacional corrobora o pressuposto inicial de que os vetores morfológicos urbanos estão mais presentes em determinadas áreas rurais e se mostram menos permeáveis em outras. Há uma escala de expressividade urbana em um gradiente de territorialidades que tem como nó propagador o Núcleo Urbano. No panorama, observamos que a busca pela agregação espacial é um comportamento predominante da população, pois todas as unidades rurais analisadas apresentaram Coeficientes de Gini da área total acima de 0,9 (Tabela 1). Essas decisões não são fundamentalmente racionais, mas expressam as relações e os vínculos sociais nas formas de organização da sociedade.

As únicas paisagens que destoam desse perfil são exatamente os Núcleos Urbanos, com Coeficiente de Gini 0,7. Nessas unidades, a população ocupa uma área proporcionalmente maior, garantindo uma distribuição mais uniforme. Nas demais Paisagens Urbanas, a população tende a se concentrar em algumas regiões, o que acaba por gerar extensas áreas com vazios populacionais ${ }^{4}$. As paisagens de

\footnotetext{
4. Espaços vazios não significam, necessariamente, áreas não utilizadas. Uma célula vazia dentro de uma Unidade de Conservação pode ser uma área florestal para manejo de base extrativista, assim como uma célula vazia ao longo das Rodovias pode ser o pasto de um latifúndio ou o lote de um agricultor familiar que reside em outro local.
} 
regularização fundiária, e, portanto, com ocupação dirigida, apresentam os menores percentuais de área ocupada: 12,7\% na paisagem Agrícola e 3,7\% na paisagem Ambiental.

\begin{tabular}{l|cc|cc|cc|cc}
\hline \multirow{2}{*}{ Paisagens Urbanas } & \multicolumn{4}{|c|}{ Área $\left(\mathrm{Km}^{2^{*}}\right)$} & \multicolumn{3}{c}{ Coeficiente de Gini } \\
\cline { 2 - 11 } & \multicolumn{2}{|c|}{ Total } & \multicolumn{2}{|c|}{ Ocupada (\%) } & Área total & \multicolumn{2}{c}{ Área ocupada } \\
\cline { 2 - 10 } & $\begin{array}{l}\text { Zona } \\
\text { BR163 }\end{array}$ & $\begin{array}{c}\text { Zona } \\
\text { BR230 }\end{array}$ & $\begin{array}{c}\text { Zona } \\
\text { BR163 }\end{array}$ & $\begin{array}{c}\text { Zona } \\
\text { BR230 }\end{array}$ & $\begin{array}{c}\text { Zona } \\
\text { BR163 }\end{array}$ & $\begin{array}{c}\text { Zona } \\
\text { BR230 }\end{array}$ & $\begin{array}{c}\text { Zona } \\
\text { BR163 }\end{array}$ & $\begin{array}{c}\text { Zona } \\
\text { BR230 }\end{array}$ \\
\hline Urbano & 220 & 135 & 79,1 & 71,1 & 0,770 & 0,794 & 0,709 & 0,709 \\
\hline Entorno urbano & 2188 & 2069 & 34,4 & 33,6 & 0,908 & 0,890 & 0,733 & 0,673 \\
\hline Rodovia & 5761 & 2897 & 24,7 & 29,0 & 0,915 & 0,887 & 0,657 & 0,612 \\
\hline A. Agrícola & 6716 & 8133 & 11,3 & 14,1 & 0,947 & 0,924 & 0,531 & 0,461 \\
\hline A. Sustentável & 16743 & 6156 & 6,2 & 0,7 & 0,978 & 0,998 & 0,645 & 0,650 \\
\hline Outras urbanidades & 10505 & 10847 & 9,4 & 12,8 & 0,959 & 0,931 & 0,565 & 0,462 \\
\hline
\end{tabular}

Tabela 1. Área ocupada* e indicadores de dispersão da população por Paisagens Urbanas nas sub-regiões de análise, 2010.

* Valor estimado considerando que cada célula contém 1 km², aproximadamente.

Fonte: Grade Estatística do Censo Demográfico 2010 (IBGE).

Confirmamos que a proporção da área sem ocupação está diretamente relacionada com o indicador de dispersão calculado para a área total - quanto menor a porcentagem da área com população, maior será o Coeficiente de Gini. Por outro lado, o indicador calculado com base somente na área ocupada apresenta variações mais marcantes (Tabela 1). A situação se reverte nessa abordagem de mensuração e o Núcleo Urbano sofre a menor variação do Coeficiente de Gini, passando a apresentar os maiores valores - assim como a paisagem Entorno Urbano. A distribuição mais homogênea no espaço ocupado ocorre na paisagem Agrícola, reflexo do processo conduzido de alocação populacional. Outra Paisagem Urbana de baixo coeficiente é Outras Urbanidades, região de ocupação espontânea supostamente sem interferência direta de vetores de estruturação espacial da população.

Os resultados obtidos para o Núcleo Urbano são insuficientes para a plena compreensão do seu processo de formação. Levando em consideração o processo histórico de cada sub-região, chama atenção a igualdade dos coeficientes de Gini para área ocupada em unidades reconhecidas pelas diferentes intensidades urbanas - apesar do mesmo grau de urbanização. Destacamos, portanto, que o padrão espacial da população nos espaços estritamente urbanos independe de sua história de consolidação, de sua densidade demográfica ou do volume da população urba- 
na. Nossa hipótese é de que esse comportamento seja universal em tais espaços - ou seja, todos os núcleos urbanos terão índices de dispersão muito próximos.

Quanto à dispersão populacional no espectro rural do tecido urbano, os resultados apontam para uma hierarquia de suscetibilidade. As paisagens Entorno Urbano e Rodovia, nessa ordem, tendem a convergir para as características do Núcleo Urbano - altos coeficientes de Gini na área ocupada e menor proporção de áreas vazias. Assim, pode-se dizer que Paisagens Urbanas com ocupação espontânea e com a presença das estruturas de fluxo e estruturação populacional são as unidades em que se verifica a maior presença dos vetores morfológicos urbanos. As áreas de ocupação controlada (paisagem Agrícola e Ambiental) são unidades com estruturas mais rígidas e menos permeáveis, sofrendo menor interferência da urbanização - o que, de certa forma, evidencia a efetividade dessas políticas no processo de controle do uso do espaço.

A força de propagação desses vetores oscila conforme as especificidades de cada unidade de análise. Na Zona-BR163, de urbanização mais antiga e avançada, observa-se que a urbanização extensiva é mais intensa. Os valores dos coeficientes de Gini são superiores em todas as Paisagens Urbanas quando comparados com o da sub-região de análise Zona-BR230 - com exceção na paisagem Ambiental, no qual apresentam valores muito próximos. A proporção da área ocupada, no entanto, não se altera conforme a sub-região de análise, e sim em função das paisagens - ou seja, pela exposição aos vetores urbanos, e não pela força destes.

Esse quadro revela que a trajetória urbana interfere nos padrões de distribuição da população rural, sem diretamente associar-se à área ocupada do espaço rural - desconstruindo a suposta relação entre urbanização e espraiamento dos espaços habitados. Estabelecemos como suposto explicativo que, na conformação do tecido urbano, ocorre a proliferação de microrregiões rurais em processo de urbanização incipiente, caracterizadas pela alta atratividade migratória. Isso inibe o movimento de expansão populacional, intensifica a concentração e acentua as morfologias urbanas - em um processo cíclico e dinâmico. Para confirmar essas evidências e avaliar se a tendência de aglomeração observada representa um processo de urbanização, leva-se em conta a composição populacional.

Reconfiguração rural e urbanização: a composição dos grupos populacionais

A análise da dispersão populacional evidenciou que os componentes presentes no Núcleo Urbano agem de forma a potencializar aglomerações populacionais rurais em uma estrutura hierárquica espacial. O mesmo efeito comparativo se verifica na escala da transição urbana - quanto mais avançado, maior o potencial de concentração. Nessa perspectiva, permanecem como lacunas os significados 
socioespaciais dos padrões de dispersão populacional derivados da combinação dessas duas dimensões. Para constatar a existência da urbanização extensiva, é preciso avaliar se a tendência de concentração, assim observada, intensifica também a expressividade urbana.

O indicador demográfico da Razão de Sexo permite observar a natureza das aglomerações considerando a tendência de feminização dos espaços urbanos e a masculinização dos espaços rurais (CAMARANO; ABRAMOVAY, 1999; DINIZ, 2002). As Figuras 2 e 3 apresentam a composição por sexo nas duas sub-regiões com base na análise espacial nas áreas ocupadas das Paisagens Urbanas. Os resultados estão organizados em gráficos de frequência acumulada dos valores de Razão de Sexo.

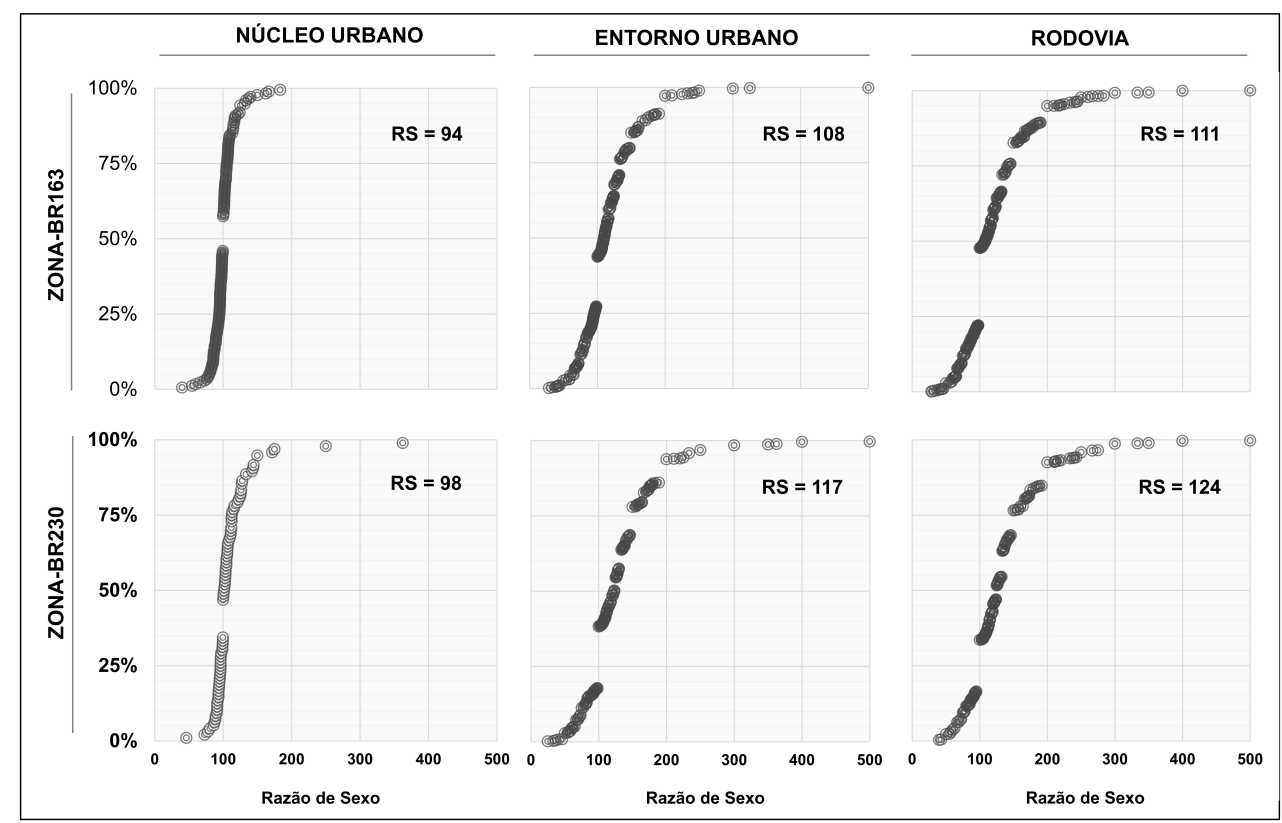

Figura 3. Razão de Sexo total e proporção acumulada* por sub-região de análise nas Paisagens Urbanas: Núcleo Urbano, Entorno Urbano e Rodovia.

*Proporção acumulada da frequência dos valores de Razão de Sexo calculados para cada célula da grade regular, IBGE.

Fonte: Grade Estatística do Censo Demográfico 2010 (IBGE). Elaboração dos autores.

Em consonância com a literatura, o Núcleo Urbano é composto em sua maioria de mulheres. Os gráficos apresentam um padrão particular, com valores oscilando muito próximos a 100 - em uma quase perpendicularidade ao eixo das ordenadas (y). Na Zona-BR230, o valor agregado da razão está muito próximo ao total equilíbrio entre os grupos. Na distribuição, a predominância de homens ocorre em $52 \%$ da área ocupada e em somente $34 \%$ as mulheres são maioria (Figura 3), o que aponta para um alinhamento com as características previstas no meio rural 
e com uma transição urbana embrionária. Em contrapartida, o urbano da Zona-BR163 confirma a feminização, com a predominância de mulheres em 46\% da área e de homens em $42 \%$ (Figura 3), o que se revela coerente com o avançado processo de transição urbana. Esse quadro reforça a limitação dos indicadores sintéticos e prova a existência de significativa diferença na expressividade urbana dos dois Núcleos Urbanos, ainda que os municípios tenham grau igual de urbanização e Razão de Sexo total abaixo de 100.

As razões de sexo no tecido urbano superam o valor 100 em todas as Paisagens Urbanas, porém variam conforme as intensidades urbanas das sub-regiões e seus contextos. Amparados pelo quadro de dispersão populacional, observamos que em áreas rurais de ocupação espontânea o processo de concentração populacional condiciona a inversão da composição desses grupos populacionais - em uma tendência de prevalência de mulheres em relação a homens. Essa transição marca a existência dos mecanismos de urbanização extensiva, em que vetores de propagação das morfologias urbanas atuam na formação de aglomerados rurais circunstanciados pela transformação das funcionalidades e também pelas significâncias dos espaços rurais - novas ruralidades ou urbanidades.

Na paisagem Entorno Urbano da Zona-BR163, 27\% da área ocupada é composta em sua maioria de mulheres, em comparação com 19\% na Zona-BR230. Somente 56\% da área ocupada na Zona-BR163 apresenta homens em sua maioria, valor que alcança $62 \%$ na Zona-BR230 (Figura 3). 0 mesmo se verifica na paisagem Rodovia, onde a prevalência de mulheres ocorre em $22 \%$ da área ocupada na Zona-BR163 e apenas em 16\% na Zona-BR230. Já a predominância de homens se verifica em 52\% na Zona-BR163 (valor inclusive abaixo do encontrado no Entorno Urbano) e em $66 \%$ na Zona-BR23o (Figura 3). Enquanto o espaço rural da Zona-BR163 é ocupado por grupos populacionais com maior presença de mulheres, dentro do esperado em espaços urbanos, na Zona-BR230 os grupos populacionais são característicos da descrição rural - com perfil similar ao obtido na paisagem Agrícola.

A paisagem Agrícola, por seu turno, apresenta o maior valor da Razão de Sexo - ao lado da paisagem Outras Urbanidades, expondo seu caráter masculino (Figura 4). O valor na Zona-BR163 é pouco menor, mas a distribuição é próxima: em média, 60\% da área ocupada tem predominância de homens e $22 \%$ de mulheres. Na paisagem Ambiental, as mulheres são maioria em $27 \%$ da área ocupada, ao passo que os homens, o são em 59\% (Figura 4). A existência de valores extremos na paisagem Agrícola justifica a diferença no valor agregado da razão de sexo em comparação com a paisagem Ambiental, que, por sua vez, é condizente com a natureza dessas unidades. De um lado, áreas que estimulam as práticas agrícolas, tradicionalmente vinculadas aos homens; de outro, o fomento ao extrativismo e 
ao uso sustentável dos recursos naturais, que propiciam condições mais atrativas para a permanência das mulheres.

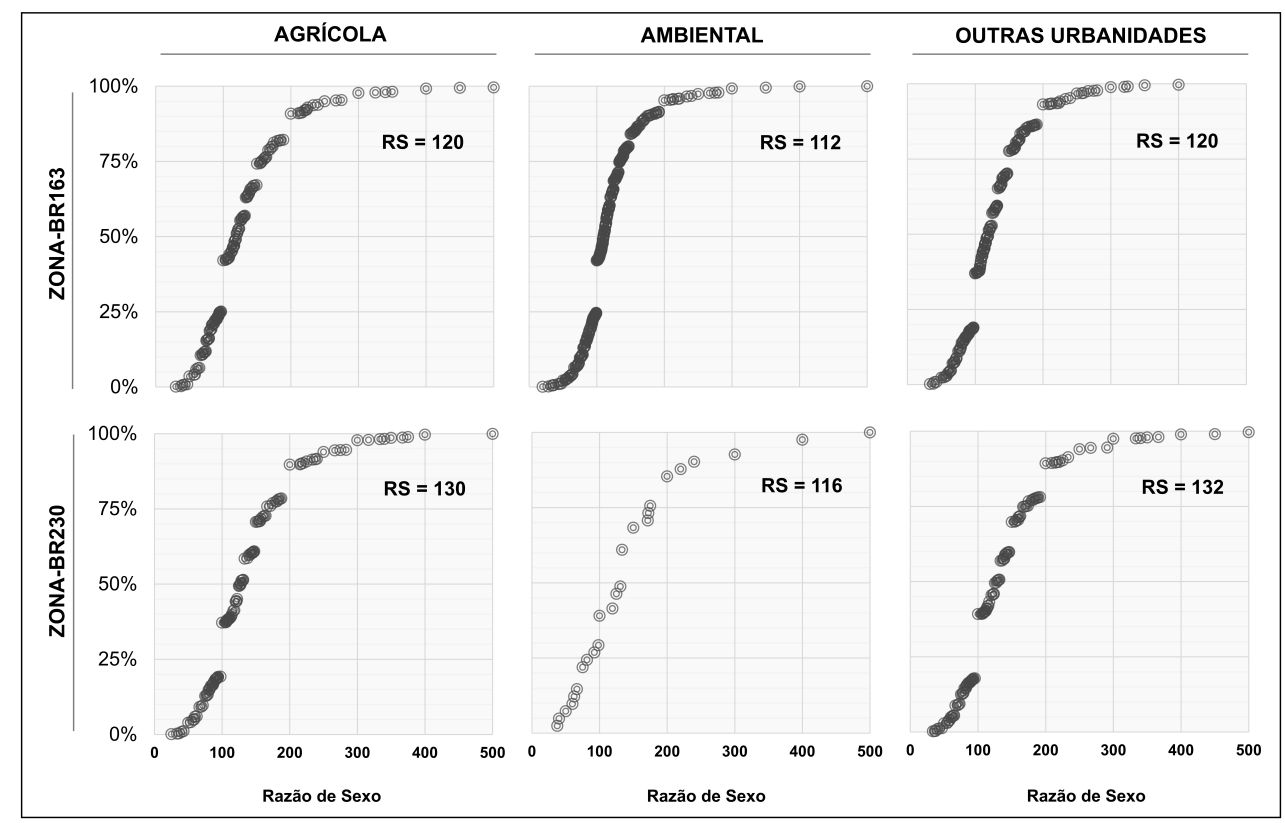

Figura 4. Razão de Sexo total e proporção acumulada* por sub-região de análise nas Paisagens Urbanas: Agrícola, Ambiental e Outras Urbanidades.

*Proporção acumulada da frequência dos valores de Razão de Sexo calculados para cada célula da grade regular, IBGE.

Fonte: Grade Estatística do Censo Demográfico 2010 (IBGE). Elaboração dos autores.

As Paisagens Urbanas de ocupação dirigida, por serem menos permeáveis aos vetores morfológicos urbanos, tampouco deveriam ser afetadas pela variação na intensidade urbana. Essa previsão é confirmada, apesar da sutil diferença nos padrões observados na paisagem Agrícola - caráter feminino mais proeminente na ZonaBR-163. Possivelmente, esses tipos de unidade são mais sensíveis aos vetores urbanos do que os pertencentes à paisagem Ambiental. A resposta a essas indagações requer estudos que incorporem os diferenciais no tempo de criação das unidades, as normativas que ditam os processos endógenos e as definições das funções sociais e ambientais da terra. Em face do que apresentamos, é possível perceber que a intervenção da urbanização é mais fraca (ou inexistente) nessas Paisagens Urbanas, o que, para o propósito deste trabalho, colabora para a percepção de que o regime de ocupação é a característica marcante nas formas de disseminação da urbanização e, em um segundo plano, a distância do núcleo urbano. 
A paisagem Outras Urbanidades é marcada pela presença masculina, em conformidade com o esperado no meio rural (Figura 4). As duas sub-regiões de análise possuem distribuição da composição praticamente igual - em média, 18\% com prevalência de mulheres e $62 \%$ de homens. A fraca interferência dos vetores urbanos também repercute na inexistência dos efeitos provocados por mudanças na intensidade urbana do polo - assim como nas áreas de regularização fundiária. Esse resultado é importante por destacar o papel fundamental dos elementos que circunstanciam a estruturação espacial da população, responsáveis por viabilizar fisicamente o fluxo de mobilidade populacional.

As análises apresentadas estabelecem uma relação entre dispersão populacional e mudança na composição por sexo desses grupos. A tendência de aglomeração é acompanhada pela feminização dos espaços em um processo de reconfiguração das paisagens rurais por meio da urbanização extensiva. Essa dinâmica, que ocorre num plano contínuo do tecido urbano, constrói um mosaico de paisagens de intensidades distintas de expressividade urbana. Destacamos três elementos responsáveis pela caracterização espacial dessa paisagem regional: a existência de um eixo de estruturação da população (que viabiliza a mobilidade), o regime de ocupação (que impõe normativas de uso) e a distância do centro urbano (que regula a força dos vetores morfológicos) - nessa ordem hierárquica de determinação.

Considerações finais: a proposta de um modelo para a urbanização extensiva na Amazônia

O estudo apresentou uma proposta metodológica que renova a discussão sobre a urbanização na Amazônia e indica como o urbano extensivo reverbera nas paisagens rurais. Como esta é uma proposta de análise inovadora, há espaço para questionamentos, aprofundamentos e aperfeiçoamentos. Em se tratando de um estudo de caso, os resultados refletem realidades específicas da região, o que aponta para a necessidade de estudos para a consolidação de um modelo que contemple a diversidade de configurações urbanas coexistentes no contexto regional amazônico. O aprofundamento empírico, seja pela ampliação regional da área de estudo, seja pela incorporação de outros estudos de caso, permite, além da validação e da realização de ajustes no modelo, a concepção de uma perspectiva compatível com a complexidade contemporânea da Amazônia brasileira.

Para novas incursões, consideramos relevante repensar o tratamento das unidades analíticas - no caso, as paisagens urbanas. Novos desdobramentos podem advir com a adoção de outros critérios na diferenciação das urbanidades no tecido urbano. Entre elas, a incorporação das vias fluviais e de outras formas de 
estruturação espacial da população, as características ecológicas e o uso e cobertura da terra. Esse processo exige a ampliação do referencial teórico sobre os fatores e mecanismos que influenciam a distribuição espacial da população na Amazônia. O esforço conjunto contribui para a criação de novas categorias de paisagem, como outras áreas de influência (buffer), subsidia as estratégias para lidar com os casos de múltiplas paisagens, com a sobreposição de unidades, e, por fim, auxilia no redimensionamento de algumas paisagens já definidas, como a redefinição do tamanho do raio do entorno urbano. Assim, consideramos que o aperfeiçoamento da unidade analítica potencializa a capacidade de análise do desenho metodológico, como resultado de ajustes na definição das paisagens urbanas e da melhor performance das análises.

Reconhecemos que ainda há no que se debruçar, mas seguramente a proposta apresentada no estudo é um ponto de partida promissor. Destacamos duas estratégias metodológicas que foram fundamentais para o resultado obtido. A primeira delas consiste no emprego de unidades escalares regulares e diminutas (as células da grade), não dependentes de limites administrativos, cuja melhor resolução espacial aprimora a análise do objeto de pesquisa. E a segunda, o uso de um indicador mais sensível aos processos sociodemográficos e espaciais em questão, algo primordial para a representação da diversidade de configurações da urbanização. Obtivemos, assim, uma diferenciação não perceptível convencionalmente pelo uso de indicadores como grau de urbanização por unidades administrativas. Evidenciou-se, assim, como duas sub-regiões com graus de urbanização semelhantes se revelam distintas.

Os resultados obtidos deixam claro que há paisagens diretamente afetadas pelo polo urbano, as quais, consequentemente, são mais suscetíveis às variações de força dos vetores morfológicos da urbanização - conforme a intensidade urbana regional na qual se insere. Essas unidades possuem um regime de ocupação espontânea e estruturas de ordenamento de fluxo populacional, como ocorre na região do entorno urbano e nas zonas de influência das rodovias. A reconfiguração dessas paisagens rurais é caracterizada pela tendência de aglomeração populacional (aumento do Coeficiente de Gini) e pela inversão da composição da população (redução da Razão de Sexo), intensificando a própria expressividade urbana em um sistema de interação complexo.

Nas demais Paisagens Urbanas analisadas, os vetores morfológicos não revelaram uma atuação transformadora perceptível. Na paisagem Outras Urbanidades, a ausência de um eixo de estruturação populacional amortece o meio de propagação desses vetores. Nas paisagens de regularização fundiária, as estruturas normativas filtram a entrada dos vetores, prevalecendo a dinâmica endógena das 
unidades - o que evidencia a efetividade dessas políticas no ordenamento da ocupação populacional. No entanto, não se descartam evidências do urbano extensivo em tais unidades, mas com ocorrência lenta. Neste caso, a reconfiguração das unidades dirigidas é orientada segundo suas especificidades.

A intensidade urbana regional é orientada pelo Núcleo Urbano de referência do tecido urbano, que, no caso do estudo em foco, são os centros urbanos municipais (e demais áreas classificadas como urbanas). Quanto menor a intensidade urbana, mais fracos serão os vetores morfológicos, favorecendo maior abertura para a reprodução dos valores rurais (presentes na sua origem remota e propagados pelas paisagens rurais no sentido reverso), em um processo que poderia ser idealizado como um urbano ruralizado (ruralização urbana) - em contramão à concepção do continuum urbano-rural, que assume somente o polo urbano como dissipador de valores e práticas. Quanto maior a intensidade e mais fortes os vetores urbanos, mais acentuados serão a reconfiguração rural e o alcance do tecido urbano, num mecanismo que pode ser descrito como a urbanização do rural. Desse balanço de fluxo de valores e relações de espaço, concebemos a ideia da dinâmica da urbanização extensiva. Com base nessa dinâmica, esboçamos uma representação da urbanização extensiva, apresentada na Figura 5, para expressar a escala de intensidade urbana e a força dos vetores de propagação das morfologias rurais e urbanas sobre as paisagens constituintes do tecido urbano.

Conforme a Figura 5, a urbanização extensiva na Amazônia é um produto da força dos vetores urbanos e rurais no eixo de intensidade urbana regional e da hierarquia das paisagens expostas a elas. A combinação desses condicionantes reflete o grau de expressividade urbana no mosaico das paisagens rurais - as urbanidades. Tendo em vista um sistema espacial contínuo na formação de um tecido urbano que se integra ao meio rural, deve ocorrer uma sobreposição de múltiplos microssistemas à medida que determinadas paisagens atingem um grau de urbanidade e passam a exercer o papel de um nó de referência urbana, constituindo um complexo modelo multiescalar.

Da perspectiva empírica, ressaltamos a pertinência do indicador de dispersão populacional na representação do grau de expressividade urbana das paisagens rurais, mesmo que limitado na determinação da expressividade do Núcleo Urbano - talvez pela delimitação ainda baseada nos critérios político-administrativos. Apresentando o mesmo Coeficiente de Gini (e grau de urbanização), porém com diferentes contextos de constituição, a intensidade urbana regional foi presumida por uma abordagem histórica e constatada somente nas análises da composição populacional (Razão de Sexo). Permanece uma lacuna quanto à diferenciação desses polos urbanos para esclarecer a formação de nós de referência e as transfor- 
mações em suas formas de distribuição, composição e ocupação do espaço. Trata-se de um entendimento fundamental para refletir sobre as estruturações analíticas relativas ao modo como se definem as paisagens urbanas. Assim, a estratégia para o aprimoramento do modelo inicia-se na compreensão desse processo construtivo dos núcleos urbanos, buscando ampliação regional para uma descrição coerente com a diversidade do quadro amazônico.

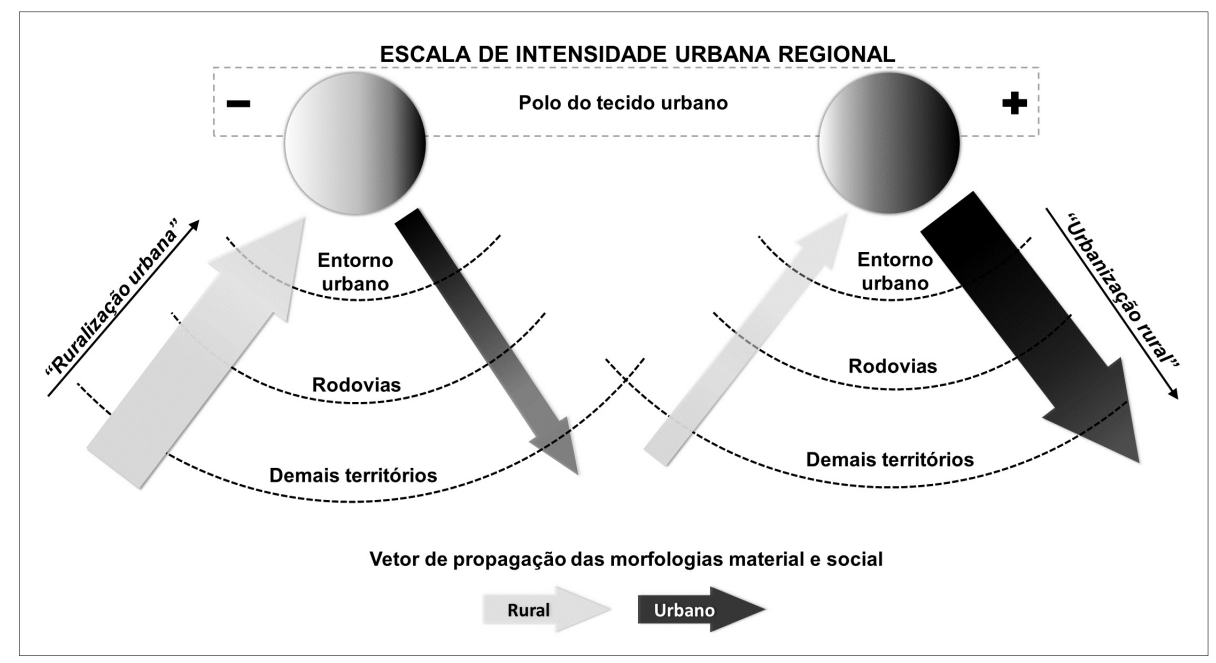

Figura 5. Representação da urbanização extensiva na Amazônia.

*As setas representam os vetores das morfologias material e social propagados espaços rural e urbano, caracterizados pela sua força (largura da seta) e alcance (gradiente de cor). Esses dois atributos variam de acordo com a intensidade urbana regional, definida pela expressividade urbana do polo de referência (centros urbanos municipais). Esses mecanismos permitem constatar o processo de urbanização extensiva, que constitui o tecido urbano no plano espacial que abarca o polo urbano e sua área de abrangência morfológica.

Fonte: Elaboração dos autores.

\section{Agradecimentos}

Os autores agradecem o apoio da Coordenação de Aperfeiçoamento de Pessoal de Nível Superior (Capes) e do Conselho Nacional de Desenvolvimento Científico e Tecnológico (CNPq) no desenvolvimento deste trabalho, por meio da concessão de bolsas de pesquisa.

\section{Referências}

BECKER, B. Undoing myths: The Amazon an urbanized forest. In: CLOSENER-GODT, M. (Org.). Brazilian Perspectives on Sustainable Development of the Amazon Region. Paris: Unesco, 1995. p. 53-89. 
BECKER, B. Revisão das políticas de ocupação da Amazônia: é possível identificar modelos para projetar cenários? Parcerias Estratégicas, v. 6, n. 12, p. 135-159, 2001.

. Geopolítica da Amazônia. Estudos Avançados, v. 19, n. 53, p. 71-86, 2005.

. A Urbe Amazônida. Rio de Janeiro: Garamond, 2013.

BRENNER, N.; SCHMID, C. Towards a New Epistemology of the Urban? City, n. 1, p. 151-182, 2015.

BROWDER, J. O.; GODFREY, B. J. Rainforest Cities: Urbanization, Development and Globalization of the Brazilian Amazon. Nova York: Columbia University Press, 1997.

CAIADO, A.; SANTOS, S. Fim da dicotomia rural-urbano? Um olhar sobre os processos socioespaciais. São Paulo em Perspectiva, v. 17, n. 3-4, p. 115-124, 2003.

CAMARANO, A.; ABRAMOVAY, R. Êxodo rural, envelhecimento e masculinização no Brasil: panorama dos últimos 50 anos. São Paulo: Ipea. Texto para Discussão (n. 621), 1999.

CASTRO, E. Prefácio. In: CARDOSO, A. C. (Ed.). O rural e o urbano na Amazônia: diferentes olhares em perspectivas. Belém: EDUFPA, 2006.

. Cidades na floresta. São Paulo: Annablume, 2009.

CHAMPION, T.; HUGO, G. Moving beyond the Urban-Rural Dichotomy. In: CHAMPION, T.; HUGO, G. (Org.). New Forms of Urbanization: Beyond the Urban-Rural Dichotomy. Nova York: Routledge, 2003. p.3-24.

COHEN, B. Urban Growth in Developing Countries: A Review of Current Trends and a Caution Regarding Existing Forecasts. World Development, v. 32, n. 1, p. 23-51, 2004.

DA COSTA, S. M. F.; ROSA, N. C. O processo de urbanização na Amazônia e suas peculiaridades: uma análise do delta do rio Amazonas. Revista Políticas Públicas \& Cidades, v. 5, n. 2, p. 81-105, 2017.

D’ANTONA, A. O.; BUENO, M. C. D. Grades estatísticas no estudo da dispersão urbana - superação dos limites das unidades administrativas e operacionais censitárias . In: OJIMA, R.; MARANDOLA JR., E. Dispersão urbana e mobilidade populacional. São Paulo: Blucher, 2016. p. 51-68

DINIZ, A. Migração e evolução da fronteira agrícola. In: XIII Encontro da Associação Brasileira de Estudos Populacionais, Ouro Preto: Abep, 2002.

ENDLICH, A. M. Perspectivas sobre o urbano e o rural. In: SPOSITO, M.; WHITACKER, A. (Org.). Cidade e campo: relações entre urbano e rural. São Paulo: Expressão Popular, 2006. p. 11-31.

FEARNSIDE, P. M. Hidrelétrica de Belo Monte \& bacia do rio Xingu. In: FEARNSIDE, P. M. (Org.). Hidrelétricas na Amazônia: impactos ambientais e sociais na tomada de decisões sobre grandes obras. Manaus: Inpa, 2015. p. 229-295.

GUEDES, G.; COSTA, S. M; BRONDÍZIO, E. S. Revisiting the Urban Hierarchy Approach in the Brazilian Amazon: a Multilevel Model Using Multivariate Fuzzy Cluster Methodology. Population and Environment, 30(4-5), 2009. 
INSTITUTO BRASILEIRO DE GEOGRAFIA E ESTATÍSTICA (IBGE). Grade estatística. Rio de Janeiro: IBGE, 2016. p. 31.

Base de informações do Censo Demográfico 2010. Rio de Janeiro: IBGE, 2010.

KAYSER, B. La Renaissance rurale. Sociologie des campagnes du monde occidental. Paris: A. Colin,1990.

LEFEBVRE, H. A revolução urbana. Belo Horizonte: UFMG, 1999.

MARQUES, M. O conceito de espaço rural em questão. Terra Livre, v. 18, n. 19, p. 95-112, 2002.

MARTINE, G.; McGRANAHAN, G. Brazil's Early Urban Transition: What Can it Teach Urbanizing Countries? Nova York: UNFPA, 2010.

MONTE-MÓR, R. Urbanização extensiva e lógicas de povoamento: um olhar ambiental. In: SANTOS, M., SOUZA, M.; SILVEIRA, M. (Org.). Território, globalização e fragmentação. São Paulo: Hucitec/Anpur, 1994. p.169-181.

. As teorias urbanas e o planejamento urbano no Brasil. In: DINIZ, C.; CROCCO, M. (Org.). Economia regional e urbana: contribuições teóricas recentes. Belo Horizonte: UFMG, 2006. p. 61-85.

MONTGOMERY, M.; STREN, R.; COHEN, B.; REED, H. Cities Transformed: Demographic Change and Its Implications in the Developing World. Washigton D.C.: National Academics Press, 2003.

PADOCH, C. et al. Urban Forest and Rural Cities: Multi-sited Households, Consumption Patterns, and Forest Resources in Amazonia. Ecology and Society, v. 13, n. 2, 2008.

PEBLEY, A. Demography and the environment. Demography, v. 35, n. 4, p. 377-389, 1998.

PEREIRA, J. C. M. P. A urbanização da Amazônia e o papel das cidades médias na rede urbana regional. In: CARDOSO, J. C. M. (Ed.). O rural e o urbano na Amazônia: diferentes olhares em perspectivas. Belém: EDUFPA, 2006.

SILVA, J. G. Velhos e novos mitos do rural brasileiro. Estudos Avançados, v. 15, n. 43, p. 37-50, 2001.

SKELDON, R. Population Mobility in Developing Countries. Londres: Belhaven, 1990.

SPOSITO, M. A questão cidade-campo: perspectivas a partir da cidade. In: SPOSITO, M.; WHITACKER, A. (Org.). Cidade e campo: relações entre urbano e rural. São Paulo: Expressão Popular, 2006. p. 111-130.

SCHMINK, M.; WOOD, C. Contested Frontiers in Amazonia. Nova York: Columbia University Press, 1992.

SCHOR, T; MARINHO, R. R.; COSTA, D. P.; OLIVEIRA, J. A. Cities, Rivers and Urban Network in the Brazilian Amazon. Brazilian Geographical Journal: Geosciences and Humanities Research Medium, v. 5, p. 258-276, 2014.

TRINDADE JÚNIOR, S. C. C. Cidades médias na Amazônia Oriental: das novas centralidades à fragmentação do território. Revista Brasileira de Estudos Urbanos e Regionais, v. 13, n. 2, p. 135-151, 2011. 
UNITED NATIONS. World Urbanization Prospects: The 2014 Revision. Nova York: Population Division, Department of Economic and Social Affairs, 2014.

WANDERLEY, M. N. B. A emergência de uma nova ruralidade nas sociedades modernas avançadas - o "rural" como espaço singular e ator coletivo. Estudos Sociedade e Agricultura, v. 15, p. 87-145, 2000. 


\section{Julia Corrêa Côrtes}

Engenheira agrônoma e demógrafa, pesquisadora de pós-doutorado no Programa de Pós-graduação em Sociedade e Ambiente do Instituto de Filosofia e Ciências Humanas (IFCH) e colaboradora do Núcleo de Estudos e Pesquisas Ambientais (Nepam), ambos da Universidade Estadual de Campinas (Unicamp).

Email: jucortes@gmail.com

ORCID: 0000-0003-1981-8200

Contribuição de autoria: investigação/pesquisa, conceituação, curadoria de dados, escrita, primeira redação.

\section{Álvaro de Oliveira D'Antona}

Cientista social, docente da Faculdade de Ciências Aplicadas (FCA) e do mestrado interdisciplinar em Ciências Humanas e Sociais Aplicadas (ICHSA); colaborador do Programa de Pós-graduação em Demografia (PPGDEM), na Universidade Estadual de Campinas (Unicamp).

Email: adantona@unicamp.br

ORCID: 0000-0003-1710-6277

Contribuição de autoria: corientação; metodologia; validação; visualização; escrita, revisão e edição.

\section{Ricardo Ojima}

Demógrafo, docente do Departamento de Demografia e Ciências Atuariais (DDCA) e do Programa de Pós-graduação em Demografia (PPGDem), ambos da Universidade Federal do Rio Grande do Norte (UFRN).

Email: ricardo.ojima@gmail.com

ORCID: $0000-0002-7472-4285$

Contribuição de autoria: conceituação; validação; visualização; escrita, revisão e edição.

Submissão: 3 de junho de 2019.

Aprovação: 26 de março de 2020.

Como citar: CÔRTES, J. C.; D'ANTONA, A. O.; OJIMA, R. Urbanização extensiva e reconfiguração rural na Amazônia: uma proposta teórico-metodológica baseada em indicadores demográficos e espaciais. Revista brasileira de estudos urbanos e regionais. v. 22, E202015, 2020. DOI 10.22296/2317-1529.rbeur.202015

Artigo licenciado sob Licença Creative Commons CC BY-NC 4.0.

https://creativecommons.org/licenses/by-nc/4.o/deed.pt_BR 